\title{
The Application of TRIZ Theory in the Design of Special Group Assisted Wheelchair
}

\author{
Peng Guoqing, Li Fuxing, Liu Chen, Zhao Yuyang \\ Xuzhou institute of technology, Xuzhou 221008, China \\ E-mail:Saintlyboy@163.com
}

Keywords: TRIZ theory; Special groups; auxiliary wheelchair; ergonomics; technical conflict; Resolve conflicts Matrix

\begin{abstract}
. whereas the special group, such as the elderly and patients, are easy to fall down in alternating between sitting and standing postures, this paper proposed to combine the TRIZE theory with ergonomics and conduct innovative design on special-group auxiliary wheelchair. by using the theory of TRIZ innovation principle and the related theory of the man-machine engineering, for the special group of improvement required auxiliary wheelchair innovative design ideas are put forward, the corresponding solution measures are made at the conflict in the process of innovation design of technology. By combining the TRIZ theory with ergonomics, an innovative practice for the special-group auxiliary wheelchair was made, which verify the application of this method can provide important for product design, development of related products design has certain reference significance.
\end{abstract}

\section{Introduction}

The elderly and patients are a special population group, especially those who are crippled, unable to take care of themselves in daily life and, most of the time, in lying or sitting postures. When they do relatively violent exercises, they are likely fall down, as their legs lack the strength to support their body. And this will be a huge hidden danger for their health. Undoubtedly, this makes wheelchair play a considerably important role in the special group's daily life. However, currently, wheelchairs are only capable of offering sitting and aided movement functions, and cannot satisfy more practical demands of the special group. To this end, this paper will utilize TRIZ theory and ergonomics to make an innovative design of auxiliary wheelchair, so as to further enhance its humanized degree.

\section{TRIZ Theory Summary}

TRIZ theory is a theoretical system of rules and principles that combine multidisciplinary fields, and it is mainly composed of 39 general engineering parameters, 40 pieces of inventive principles, $39 \times 39$ conflict resolution matrices and $\operatorname{such}[1]$. The application of TRIZ theory to product innovative design mainly provides design thinking by the conflict resolution matrix of TRIZ theory and solves the technical conflicts that occur in the process of innovative design, so as to achieve the goal of optimizing the product functions. Firstly, turn the functional deficiency in product use process into standard problem and find out its technical resolution; secondly, describe the already-determined technical conflict by applying the 39 general engineering parameters of TRIZ theory, obtain the related engineering parameter based on the descriptions, and then use the engineering parameter-composed conflict resolution matrix to find related inventive principle; lastly, on the basis of an in-depth understanding of inventive principle, organize and apply the grasped knowledge to search the best thinking for conflict resolution.

\section{Application Practice of TRIZ Theory}

\section{Problem Analysis of Auxiliary Wheelchair}

Currently, wheelchairs designed for the crippled are only capable of offering siting and aided 
movement functions. In addition, different types of wheelchairs are targeted at varied groups. For example, the controllable, mobile power-assisted wheelchairs are mainly targeted at those who are disabled in the lower limbs, so as to better satisfy their demand for free movement. However, to those who have difficulties in sitting stably, these wheelchairs have no auxiliary sitting function. Moreover, in most cases, the special population group will use wheelchairs in daily life. For example, while shifting from sitting posture to sitting posture, they are likely to fall down, as their legs lack the strength to support their body, which will lead to a huge hidden danger for their health, as can be seen in Figure 1.

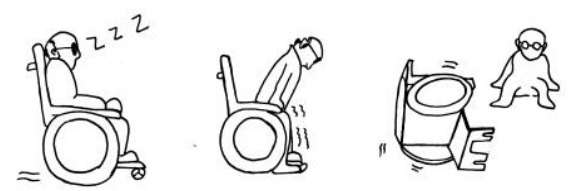

\section{Description of Technical Conflict}

Fig 1. The specific embodiment of wheelchair

The aforesaid problems can be resolved by adding the functions of auxiliary wheelchair, so that it can meet more practical demands of the special population group. However, this will lead to a problem--weight increment of wheelchair; in addition, to cater to the need of a special group--the crippled, the automation degree of wheelchairs can be improved to facilitate the operation, but it will make the morphological structure of wheelchair more complicated. Therefore, in utilizing TRIZ theory to make an improved design of auxiliary wheelchair, its functions and weight will increase as well; improvement of automation degree and growing complexity of wheelchair's morphological structure constitute a technical resolution, and then this technical resolution can be turned into 39 general engineering parameters of TRIZ theory, which are respectively as follows:

No.35 adaptability and versatility: it refers to the possibility that an object or a system, under the influence of external factors, will give play to its functions in many ways[2]; it shall be an improved parameter; weight of No. 1 moving object: it refers to the force the moving object, in the gravitational field, imposes on the upholder that prevents it from free falling down.

No.38 automation degree: it refers to ability that an object or a system realizes its abilities in case of unmanned operation and it's an improved parameter; No.12 shape: it refers to the morphological contour or appearance of an object.

\section{Determination of Inventive Principle}

Determine its technical resolution by analyzing the improved functions of auxiliary wheelchair and, by checking the conflict resolution matrix list of TRIZ theory, the inventive principle required for solving technical conflict can be obtained: by checking the first set of conflicts, No.1, 6,8 and 15 inventive principles can be obtained; by checking the second set of conflicts, No.1, 13, 32 and 15 inventive principles can be obtained, as shown in Tab 1.

Tab 1.The Conflict resolution matrix

\begin{tabular}{|c|c|c|c|c|c|c|}
\hline $\begin{array}{l}\text { Deteriorated General } \\
\text { Engineering } \\
\text { Parameter }\end{array}$ & $\begin{array}{l}\text { No.1 weight of } \\
\text { moving object }\end{array}$ & $\begin{array}{c}\text { No.2 } \\
\text { Weight of static } \\
\text { object }\end{array}$ & $\ldots$ & No.12 shape & $\ldots$ & No.39 productivity \\
\hline No.1 weight of moving object & - & - & $\ldots$ & $\begin{array}{l}10,14 \\
35,40 \\
\end{array}$ & $\ldots$ & $\begin{array}{r}35,3 \\
24,37 \\
\end{array}$ \\
\hline$\cdots$ & ... & $\cdots$ & $\ldots$ & $\ldots$ & $\ldots$ & $\ldots$ \\
\hline $\begin{array}{l}\text { No. } 35 \text { applicability and } \\
\text { versatility }\end{array}$ & $\begin{array}{c}1,6 \\
15,8\end{array}$ & $\begin{array}{l}19,15 \\
29,16\end{array}$ & $\ldots$ & $\begin{array}{c}15,37 \\
1,8\end{array}$ & $\ldots$ & $\begin{array}{c}35,28 \\
6,37\end{array}$ \\
\hline$\ldots$ & $\ldots$ & & $\ldots$ & $\ldots$ & $\ldots$ & $\ldots$ \\
\hline No. 38 automation degree & $\begin{array}{l}28,26 \\
18,35\end{array}$ & $\begin{array}{l}28,26 \\
35,10\end{array}$ & $\ldots$ & $\begin{array}{c}15,32 \\
1,13\end{array}$ & $\ldots$ & $\begin{array}{c}5,12 \\
35,26\end{array}$ \\
\hline No. 32 productivity & $\begin{array}{l}35,26 \\
24,37\end{array}$ & $\begin{array}{c}28,27 \\
15,3\end{array}$ & $\ldots$ & $\begin{array}{l}14,10 \\
34,40\end{array}$ & $\ldots$ & \\
\hline
\end{tabular}

By combining the practical problems to be solved for auxiliary wheelchair, screen and analyze all obtained inventive principles and, at last, No 6,13 and 15 inventive principles are selected to serve as the guiding ideology for the innovative design of auxiliary wheelchair. The specific 
interpretations of different inventive principles are shown in Tab 2.

Tab 2.Optimal principle and explanation

\begin{tabular}{|c|c|l|}
\hline $\begin{array}{c}\text { Serial } \\
\text { Number }\end{array}$ & $\begin{array}{c}\text { Name of } \\
\text { Principle }\end{array}$ & \multicolumn{1}{|c|}{ Interpretation of Principle } \\
\hline $\mathbf{6}$ & Poly-functionality & $\begin{array}{l}\text { Enable one object to complete many functions, so as to reduce the } \\
\text { number of objects required for completing these functions in the } \\
\text { original design. }\end{array}$ \\
\hline $\mathbf{1 5}$ & Dynamism & $\begin{array}{l}\text { 1) enable one object or its environment to adjust automatically at each } \\
\text { operation stage, so as optimize its performance: (2) if one object is } \\
\text { static, make it mobile or changeable. }\end{array}$ \\
\hline $\mathbf{1 3}$ & reversal & $\begin{array}{l}\text { 1) change a regulated operation in one problem to a reverse operation: } \\
\text { 2) enable the moving part of one object to become static and static part } \\
\text { moving. }\end{array}$ \\
\hline
\end{tabular}

No. 6 Poly-functionality: increase the functions of auxiliary wheelchair as appropriate, so that it can, on the basis of its basic sitting function, add aided sitting and stretcher-like functions; No.13 reversal theory: it makes the originally-moving people kept in a static state while the seat surface of auxiliary wheelchair can rise and fall at an appropriate speed, so that it can help shift siting and standing postures[3]; No.15dynamism theory: it enables auxiliary wheelchair to adjust dynamically according to the fatigue degree and function needs, so as to shift siting, standing and lying postures. The specific design implementation of different optimization theory is shown in Figure 2.

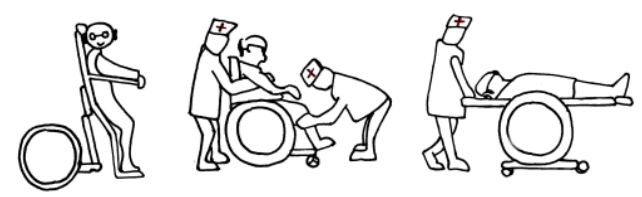

Fig 2 . The design and implementation of invention principles

\section{Specific Design of Auxiliary Wheelchair}

\section{Design Concept of Auxiliary Wheelchair}

Plan 1:Customized for those with limited walking ability, this design uses a storage box between two wheels,from which a soft cloth can stretch out to form a seat cushion; contract the soft cloth into the storage box, turn the pedal upside leaning on the back of wheels, so that the wheelchair can be capable of auxiliary sitting and aided walking functions; Plan 2: when people need to stand up, they can use the force the feet exert on the pedal to adjust the lifting speed of seat surface; this design will be relatively difficult for those with powerless legs, as it's not easy to control the force exerted on the pedal, and it lacks the auxiliary walking function; Plan 3: the armrest of wheelchairs applies induction design-when users need to stand up, they need to exert external force on the armrest and can adjust the lifting speed of seat surface by the size of external force; Plan 4: in addition to providing sitting function, it can also enable users to shift different postures according to the fatigue degree and provide the special group with auxiliary standing and sitting functions by lift remote control on the seat surface, as shown in Figure 3.
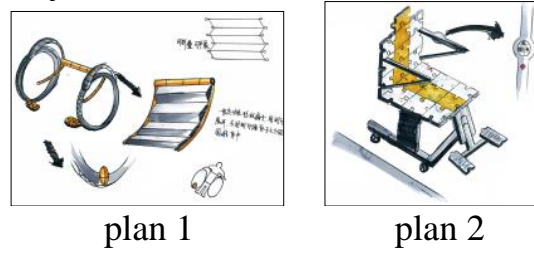

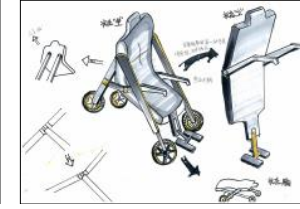

plan 3

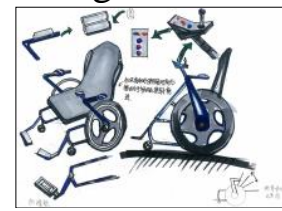

plan 4

\section{Determination of Final Plan}

Fig 3. The ideas of the performance of assisted wheelchair

By analyzing comparing different design plans, plan four is selected out as the best one, with its final effect shown in Figure 4. 

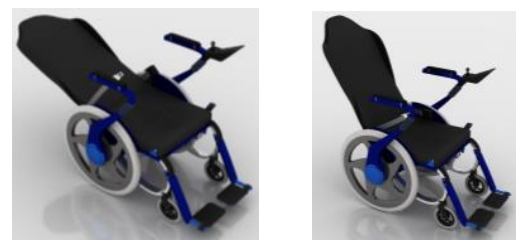

Fig 4. The final result

This auxiliary wheelchair has many functions. In addition to the basic sitting functions, it enables users to shift sitting, lying, standing and other postures according to their fatigue degree, and control the lifting of seat surface by the joystick on the left armrest; moreover, an emergency pill box is additionally installed on the right armrest, which can be convenient for the special population group to use the pills in emergency conditions. The "human-machine coupling" verification scenario for the auxiliary wheelchair designed is shown in Figure 5.
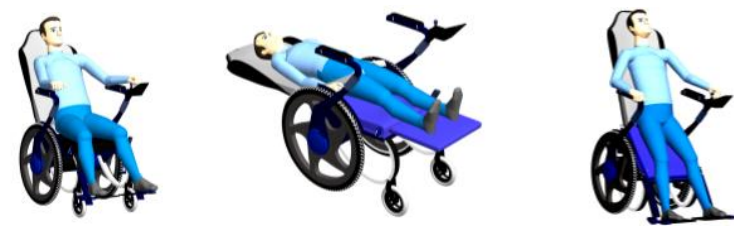

Fig 5. Man - machine coupling verification

\section{Determination of Dimensions of Auxiliary Wheelchair}

The assumptions of related dimensions of auxiliary wheelchairs will be determined in accordance with the sitting hip breadth, sitting elbow height, lower leg-foot length, stature and other measured data, as shown in Tab 3.

Tab 3. The related body size data

\begin{tabular}{|c|cccc|cccc|}
\hline & \multicolumn{7}{|c|}{ Male(18 60) } & \multicolumn{5}{|c|}{ Female(18 55) } \\
\hline Percentile & 1 & 5 & 95 & 99 & 1 & 5 & 95 & 99 \\
Item & & & & & & & & \\
\hline $\begin{array}{c}\text { Sitting hip breadth } \\
/ \text { mm }\end{array}$ & 284 & 295 & 355 & 369 & 295 & 310 & 382 & 400 \\
\hline $\begin{array}{c}\text { Sitting elbow height } \\
/ \text { mm }\end{array}$ & 214 & 228 & 298 & 312 & 201 & 215 & 284 & 299 \\
\hline $\begin{array}{c}\text { lowerleg-foot length } \\
/ \text { mm }\end{array}$ & 372 & 383 & 448 & 463 & 331 & 342 & 405 & 417 \\
\hline Stature / mm & 1543 & 1583 & 1775 & 1814 & 1449 & 1484 & 1659 & 1697 \\
\hline
\end{tabular}

In the process of applying anthropological data to set the dimensions of wheelchair, functional correction, psychological correction and other values should be added to the related percentile of human body dimensions, as shown in Tab 4[4].

Tab 4. The correction amount of Body size

\begin{tabular}{|c|c|c|}
\hline Item & $\begin{array}{c}\text { Dimension } \\
\text { Correction }\end{array}$ & $\begin{array}{c}\text { Reason for } \\
\text { Correction }\end{array}$ \\
\hline $\begin{array}{c}\text { Elbow to elbow } \\
\text { shoulder breath }\end{array}$ & $20 \mathrm{~mm}$ & Thick coat \\
\hline Sitting hip breath & $13 \mathrm{~mm}$ & Thick coat \\
\hline Standing height & $25 \sim 38 \mathrm{~mm}$ & Tall shoes \\
\hline
\end{tabular}

In applying anthropological data, select the appropriate type of human body dimensions on the basis of product functions, and determine the percentile. In the GB/T12985-1991 standard, product dimension design is divided into three types, I, II and III. Wherein, II type is divided into IIA and IIB. In applying IIA and IIB to conduct product design, one percentile of human body dimension is enough to serve as the basis for upper and lower limiting values[5].

The auxiliary wheelchair tailed for special population group is related to people's health and safety. Based on its folded "total length", it belongs to "IIA-type large dimension design". So P99 is selected as the basis for determining the dimensions. According to the data provided in GB1000-1988 standard, "height of male $\mathrm{P}_{99}$ " is $1814 \mathrm{~mm}$, while t"hat of female $\mathrm{P}_{99}$ " is $1697 \mathrm{~mm}$. Therefore, based on the height of male, the "total length" can be determined according to the 
formula (1):

$$
H=I+a_{1}+a_{2}
$$

Wherein, $\mathrm{H}$ - total length of wheelchair in lying posture, $\mathrm{mm}$;

I-height of male $\mathrm{P}_{99}$, $\mathrm{mm}$;

$a_{1}$ - functional correction of shoes, namely, thickness of shoes, $\mathrm{mm}$;

$a_{2}$ - psychological correction, $\mathrm{mm}$.

In the aforementioned formula, the thickness of shoes $a_{1} \mathrm{~s}$ set as $35 \mathrm{~mm}$; since psychological correction cannot be subjectively determined as a certain specific value, it shall be obtained by making a statistical analysis of results of testate subjective evaluation form, so the psychological correction $a_{2}$ is set as $30 \mathrm{~mm}$. Therefore, the optimum functional dimension of the total length of auxiliary wheelchair is $1879 \mathrm{~mm}$ and after being rounded up, the final length is set as $1880 \mathrm{~mm}$.

According to the determination of seat surface height of auxiliary wheelchair, it should be "IIB small dimension design". To cater to the need of the majority of special population group and avoid bending one's knees, the lower leg-foot length of " female P99" is selected as the standard for determining dimensions. According to the data provided in GB10000-1988, the lower leg-foot length of "female P99" is $417 \mathrm{~mm}$ and after being rounded up, the seat surface height of auxiliary wheelchair is set as $430 \mathrm{~mm}$.

The "seat surface breath" of auxiliary wheelchair belongs to IIA-type large dimension design. According to the dimensional data provided in GB10000-1988 standard, "sitting hip breadth of female P99" is $400 \mathrm{~mm}$, while "that of male P99" is $369 \mathrm{~mm}$, so the "sitting hip breadth of female P99" is selected as the standard for determining the dimensions; in addition, the functional correction of $13 \mathrm{~mm}$ in dressing state is added, according to the formula (2):

$$
W=w+b_{1}+b_{2}
$$

Wherein: W- seat surface breadth, mm;

w-sitting hip breadth of female $\mathrm{P}_{99}, \mathrm{~mm}$;

$b_{1}$-dressing correct, $\mathrm{mm}$.

$b_{2}$ - psychological correction, mm.

In the aforementioned formula, $b_{1}$, dressing correction, is set as $13 \mathrm{~mm}$. Since psychological correction cannot be subjectively determined as a certain specific value, it shall be obtained by making a statistical analysis of results of testate subjective evaluation form, so the psychological correction $b_{2}$ is set as $30 \mathrm{~mm}$. Therefore, the optimum functional dimension of the sitting breadth of auxiliary wheelchair is $443 \mathrm{~mm}$ and after being rounded up, it's set as $450 \mathrm{~mm}$.

According to the determination of "height of armrest" of auxiliary wheelchair, its dimensional design belongs to "IIB small dimension design". To cater to the need of the majority of special population group, the "sitting elbow height of female $\mathrm{P}_{5}$ " is selected as the basis for determining dimensions. According to the data provided in GB10000-1988 standard, the "sitting elbow height of female $\mathrm{P}_{5}$ " is $215 \mathrm{~mm}$ and after being rounded up, the height of armrest of wheelchair is set as $220 \mathrm{~mm}$, as shown in Figure 6.
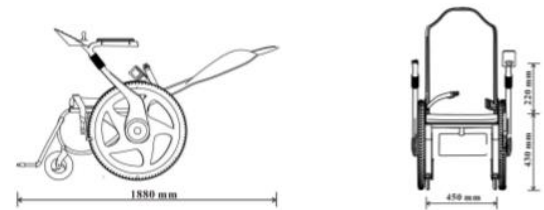

Fig 6. The determined sizes of Auxiliary wheelchair

\section{Conclusion}

The application of the conflict resolution principle in TRIZ theory to the design practice of auxiliary wheelchair mainly makes innovations from the following aspects:(1) By controlling the lifting speed of seat surface, it assists the special population group with sitting and standing and avoids accidents';(2) The dynamic adjustment of backrest angle of wheelchair achieves shifting of 
functions, ranging from wheelchair, stretcher to other functions. Not only can it be used in different conditions, but also it greatly improves comfort ability;(3) The addition of emergency pill box function highlights the humanized design concept of auxiliary wheelchair and satisfies emergency needs.

\section{References}

[1] ZHAO Yan-jiang. Design on vane cleaning machine for soot absorbed based on TRIZ theory [J]. Journal of Machine design, 2010,(2):70-73.

[2] LI Fu-xing. Innovation design of road roller based on the conflict solving principle of the TRIZ[J].Journal of Machine design,2014(9):109-112.

[3] FU min. Reviews on integrated innovation methods for TRIZ-based product design[J].Chinese Journal of Construction Machinery,2013(4):170-174.

[4] WANG Xiu-hong. Innovative Design of Electric Vacuum Blackboard Eraser Based on QFD and TRIZ [J].Packaging Engineering, 2014,35(9):39-42.

[5] LI Fu-xing. Study on the application of ergonomics in the design of repairing lying plate[J].Journal of Machine design, 2013(11):104-107. 